\title{
BILDUNG E SEGUNDA NATUREZA: MCDOWELL LEITOR DE GADAMER
}

\author{
Bruna Natália Richter ${ }^{1}$ \\ Universidade Federal de Santa Maria (UFSM) \\ https://orcid.org/0000-0002-7946-7249 \\ E-mail: brunataliarichter@gmail.com
}

\section{RESUMO:}

Em seu livro Mente e Mundo John McDowell pretende superar a oscilação entre duas abordagens que pretendem mediar à relação entre as mentes e o mundo, de um lado temos o mito do dado dizendo que os pensamentos precisam de uma coerção a partir do mundo exterior, e do outro lado temos o coerentismo que apresenta a ideia de que apenas uma crença pode justificar outra crença. Para defender sua abordagem e naturalizar as capacidades conceituais, situando a espontaneidade na natureza sem reduzi-la no interior do reino da lei. A natureza humana seria então uma segunda natureza que não é só formada a partir das capacidades adquiridas no nascimento, mas que são formadas também a partir da Bildung. Ao lançar mão dessas noções, McDowell traz a discussão das ideias de Han-Georg Gadamer sobre a experiência de abertura para o mundo através da linguagem. Deste modo, a intenção do presente artigo é de discutir sobre as implicações das noções de Bildung e segunda natureza na obra de McDowell buscando um maior esclarecimento a partir da influência e das interpretações de Gadamer.

PALAVRAS-CHAVE: Bildung; Segunda natureza; McDowell; Espontaneidade.

\section{BILDUNG AND SECOND NATURE: MCDOWELL GADAMER READER}

\begin{abstract}
:
In his book Mind and World, John McDowell intends to overcome the oscillation between two approaches that seek to mediate the relationship between the minds and the world, on the one hand we have the myth of the giving saying that thoughts need coercion from the outside world, and on the other side we have the coherentism that presents the idea that only one belief can justify another belief.To defend its approach and naturalize conceptual capabilities, situating spontaneity in nature without reducing it within the realm of law. Human nature would then be a second nature which is not only formed from the abilities acquired at birth but which are also formed from the Bildung. In taking these notions, McDowell brings the discussion of Han-Georg Gadamer's ideas about the experience of openness to the world through language. In this way, the intention of the present article is to discuss about the implications of the notions of Bildung and second nature in the work of McDowell seeking a greater clarification from the influence and the interpretations of Gadamer.
\end{abstract}

KEYWORDS: Bildung; Second nature; McDowell; Spontaneity.

1 Doutoranda em Filosofia na Universidade Federal de Santa Maria (UFSM), Santa Maria - RS, Brasil.

RICHTER, Bruna Natália. Bildung e segunda natureza: Mcdowell leitor de Gadamer. Griot : Revista de Filosofia, Amargosa-BA, v.19, n.1, p.186-196, fevereiro, 2019. 


\section{Introdução}

Uma certa imagem da relação que a nossa mente possui com o mundo precisa ser "exorcizada", segundo John McDowell, dos pressupostos que nos levam a oscilar apenas entre duas teorias. Para isso, torna-se necessária uma análise que nos ajude a esquivar e, consequentemente, responder os problemas que são nos apresentados a partir de uma tendência da filosofia em oscilar entre duas teorias, de um lado temos o mito do dado defendido por Sellar, e G. Evans, e do outro lado o coerentismo defendido por Davidson, nos coloca entre duas posições, de um lado a ameaça de perder a conexão entre pensamento empírico e uma realidade independente, do outro lado à espontaneidade que é uma ideia de liberdade ameaça levará fim o pensamento empírico num giro sem atrito.

Não obstante, a filosofia de McDowell tratará sobre uma análise do problema que repassa a percepção, aos conteúdos dessa percepção que para ele são conceituais e da experiência do mundo. O fundamento de sua empreitada reside na não separação entre a sensibilidade e a espontaneidade, posição essa originada do desencantamento da natureza a partir da modernidade. Para resolver esse impasse, McDowell retornará a ética aristotélica e a partir do conceito de sabedoria prática retomar a ideia de uma segunda natureza. Para assim, dar lugar para a espontaneidade do entendimento nessa concepção de segunda natureza. Nesse ponto se faz interessante tratar das críticas de Hilary Putnam para clarificar as concepções e a filosofia de McDowell e colocar em xeque os seus principais conceitos, assim como questionar a tendência da naturalização da razão.

A partir de relocação da espontaneidade na natureza, sem reduzi-la e alterar o que entendemos a partir dela, torna a razão como sendo uma forma que os seres humanos possuem da natureza. Essa posição de McDowell só se tornará completa ao apresentar o conceito de Bildung que se origina na hermenêutica filosófica de Gadamer e sua análise da linguagem como abertura para o mundo para os seres humanos. Deste modo, a presente discussão tem como objetivo uma análise da filosofia de McDowell através da filosofia de Gadamer que pretende lançar luzes sobre alguns pontos como experiência perceptiva, conceito de formação e o de segunda natureza, intento que ao inverso do que realiza Morthe $S$. Thaning que explora o problema da objetividade de Gadamer com luzes a filosofia de McDowell.

\section{Abertura para o mundo}

Em Mente e Mundo John McDowell pretende discutir o modo como conceitos podem mediar à relação entre a mente e o mundo, essa análise trará a tona conceitos como de razão, experiência, justificação, causas e leis naturais. O Propósito da empreitada de McDowell é mostrar a tendência que possuímos de oscilar entre duas teorias, de um lado o coerentismo defendido por D. Davidson que tem como principal problema a desconexão entre pensamento e realidade, e de outro lado, o mito do dado defendido por G. Evans e W. Sellars que diz que "simples presenças" (MCDOWELL, 2005, p.61) deveriam fundamentar nossos juízos sobre o mundo.

Não obstante, se faz importante apresentarmos a visão de Kant sobre as faculdades que trataremos, como sensibilidade e espontaneidade. Colin McLear 
(2014) nos apresenta que, segundo Kant, a faculdade responsável pelas representações sensórias que se formam a partir da afecção do sujeito pelo mundo é a sensibilidade, em contrapartida, a espontaneidade pertence ao entendimento que é responsável pela capacidade conceitual. Assim, ao falar sobre posição de Kant, McDowell específica que aceitar essa posição, "significa reconhecer que o ato de julgar é um emprego ativo de capacidades que nos dão o poder de assumir o comando de nossos pensamentos." 2 (2005, p. 103), isso quer dizer, que a espontaneidade está sempre ativa em nossas capacidades. A experiência perceptiva só é inteligível, para nós, quando está em jogo a capacidade racional, no momento em que recebemos os dados do sentido, embora ela não envolve um pensamento ativo estão envolvidas capacidades conceituais. Esse traço de atribuição de um significado racional para a experiência é segundo McDowell um "insight fundamental do empirismo" (2006, p. $147)^{3}$. As experiências seriam ocorrências em que a espontaneidade estaria em funcionamento até mesmo nas realizações da receptividade.

O pensamento precisa, segundo McDowell, de uma coerção externa ao pensamento que se dá a partir da origem da experiência que ocorre na receptividade operante do sujeito. $\mathrm{O}$ mito do dado concede uma limitação externa para o exercício da espontaneidade, essa limitação ocorre a partir da afecção dos impactos vindo do exterior. Porém essas meras presenças não são capazes de nos darem a limitação racional necessária para justificar nosso pensamento empírico, como aponta Stefano Di Brisco (2010, p. 121). Contudo, no "mito do dado" esse fato impede que a experiência cumpra seu papel na justificação das crenças, o mito dado oferece apenas "exculpações no lugar de justificações". Ao abandonar o mito do dado de um lado, caímos do outro no coerentismo, que como Di Brisco aponta, quando reconhecemos que uma experiência por si só não sustenta uma crença, então "apenas uma crença pode sustentar outra crença" "nos confinando na espera do pensamento" (2010, p. 121). Isso nos coloca na posição que McDowell chama de "spinning in the void" (num giro sem atrito).

Nesse ponto que o conteúdo conceitual entra, como sendo o motivo que não impediria tal justificação a partir das experiências. Nas palavras de McDowell,

Ao ser recepcionado na experiência, o modo como as coisas são torna-se disponível para impor a nosso exercício de espontaneidade o controle racional necessário vindo de fora. ${ }^{4}(2005$, p.63)

A realidade está aberta para nós a partir da capacidade de afecção que possuímos, do modo como a identificamos nas representações, a realidade delimita, ou como McDowell expressa, "impõe uma marca" sobre o sujeito que a percebe. A realidade é independente do nosso pensamento assim como a experiência que produz

\footnotetext{
2 . Trecho completo, To accept that point is to acknowledge that judging is na active employment of capacities that empower us to take charge of our thinking. (1996, p. 66)

3 . Trecho completo da afirmação de McDowell sobre o empirismo em que está engajado, segundo ele, "Penso que atribuir esse significado racional à nossa experiência perceptiva é um insight fundamental do empirismo. Tentei mostrar que, para acomodá-lo, nós precisamos conceber nossa experiência perceptiva como uma realização, na consciência sensorial, de capacidades conceituais." (2006, p.147).

4. By being taken in in experience, how things anyway are becomes available to exert the required rational control, originating outside one's thinking, on one's exercises of spontaneity. (1996, p. 26).
}

RICHTER, Bruna Natália. Bildung e segunda natureza: Mcdowell leitor de Gadamer. Griot : Revista de Filosofia, Amargosa-BA, v.19, n.1, p.186-196, fevereiro, 2019. 
em nós, isso quer dizer que o pensamento por si só não produz essa experiência, ele precisa da afecção do mundo, no entanto, ela não será imaginada "fora do limite externo" das nossas capacidades conceituais em jogo na afecção.

A experiência possui certo tipo de inteligibilidade própria que se dá a partir da espontaneidade do entendimento. A experiência controla o pensamento assim como dá razões para tal. Ela é uma forma de abertura para o mundo, que já é conceitualizada e, por isso, pertencente ao espaço das razões. A noção de espaço das razões (de Sellars) é a conexão que dá sentido ao que McDowell entende por intencionalidade que se dá entre normatividade e linguagem, deste modo, ao caracterizarmos um estado como sendo intencional estamos dizendo que ele pertence ao espaço das razões. Não obstante, entre esse espaço lógico das razões e o espaço lógico das leis há um contraste de gênero e inteligibilidade cuja dicotomia abre espaço para a hermenêutica filosófica de Hans-Georg Gadamer que trata da diferença entre o explicar e o compreender, isso quer dizer que o explicar as conexões naturais e compreender o sentido dessas conexões. $O$ conteúdo da experiência pode ser proposicional, assim como não é negado em Gadamer que assertivas com uma proposição podem representar o mundo, mas que o significado das asserções não está totalmente presente, mas é alcançado quando entendemos a asserção. McDowell mudará sua posição a respeito do conteúdo da experiência ser proposicional em trabalhos posteriores.

Deste modo, quando a experiência torna o conteúdo conceitual disponível pra alguém é a sensibilidade operando e não o entendimento, é a sensibilidade que nos apresenta o mundo como é. A receptividade é a responsável por assegurar a afecção, mas as capacidades da espontaneidade estão sempre em jogo principalmente na fundamentação das bases dos juízos empíricos. Como diz McDowell,

Se quisermos evitar a ameaça de vacuidade, precisamos ver as intuições mantendo relações racionais com aquilo que devemos pensar, e não mantendo apenas relações causais com aquilo que de fato pensamos $(2005$, p. 105$)^{5}$

Os conteúdos conceituais do entendimento colocam os juízos que formamos na percepção no espaço das razões, assegurando essas "relações racionais". Não obstante, no que toca o conteúdo das experiências perceptivas, McDowell aponta as várias razões que G. Evans discute quando afirma que o conteúdo dessas experiências é não-conceitual. Uma dessas razões nos traz a ideia de sistema informacional que seria um sistema mais primitivo que dividimos com os demais animais, sendo mais simples que as capacidades da espontaneidade que apenas seres humanos possuem. Nesse sistema tanto a memória quanto a percepção pertencem a todos os animais, no entanto, como as experiências participam desse sistema informacional, elas só podem ter um conteúdo não-conceitual ${ }^{6}$.

\footnotetext{
5 Thoughts without intuitions would be empty, as Kant almost says; and if we are to avert the threat of emptiness, we need to see intuitions as standing in rational relations to what we should think, not Just in casual relation to what we do think. (1996, p. 68).

${ }^{6}$ Para saber mais sobre a discussão de Evans com McDowell sobre o conteúdo das experiências, leia BOYLE, Matthew. Additive Theories of Rationality: A Critique. In: European Journal of Philosophy, 2016. E para uma
} 
Para Matthew Boyle (2016) o argumento de McDowell sobre a natureza dos conteúdos serem conceituais não parece depender desses conteúdos serem de fato conceituais. Deste modo, essa atribuição apenas implica certo tipo de engajamento das capacidades. Boyle diz que a argumentação é formada desse modo apenas para erguer uma dificuldade para as teorias que defendem o não-conceitualismo. (2016, p. 9)

\section{Bildung}

Os conceitos pertencem ao espaço das razões, então ao adquirir e utilizar a linguagem estamos nos movendo nesse âmbito e não somente no domínio das leis da natureza. Ao adquirir a linguagem ganhamos uma nova abertura para o mundo, abertura essa que muda a forma como interagimos, orientamos o entendimento e a forma como vivemos no mundo. McDowell remete essa abertura para o mundo pela linguagem, para a filosofia ética de Aristóteles e a sabedoria prática assim como para o conceito de Bildung proveniente principalmente da hermenêutica filosófica de Gadamer. Por isso se torna interessante discutir o pensamento de Gadamer a respeito da formação.

Nas primeiras sessões de Verdade e Método (2014) Gadamer discute algumas concepções humanistas, entre elas a de formação (Bildung). Nesse ideal de formação, o senso comum desempenha um papel relevante para a elevação ao universal, na construção de algo comum e justo para as ciências do espírito contra o ideal de método único das ciências - cuja qual o conceito de formação não desempenha um papel central. Para o filósofo alemão, o conceito de formação está conectado com o conceito de cultura e em suas palavras compreende "a maneira especificamente humana de aperfeiçoar suas aptidões e faculdades." (2014, p. 45), a Bildung é um ideal pertencente exclusivamente aos seres humanos de busca e aprimoramento de suas características assim como de sua própria personalidade, subjetiva e cultural.

Jean Grondin aponta para as críticas de Vattimo sobre o problema da objetividade em relação às hermenêutica de Gadamer. Vattimo parte da ideia de Verdade e Método que diz "ser que pode ser entendido é linguagem" que ao afirmar isso Gadamer estaria afirma que o entendimento do ser humano não pode ser relato para as coisas em si mesmas, mas somente daquilo que podemos falar sobre elas. $O$ modo como falamos das coisas é sempre a partir da nossa perspectiva histórica. Porém, para Gadamer não existe nenhum entendimento que não seja seguido de prejuízos, nossos pontos de vistas estão sempre relatados a tradição que estamos inseridos. Deste modo, todo nosso entendimento é naturalmente linguagem. Grondin nos mostra que o ser ou mesmo as coisas em si não podem ser reduzidas a mera linguagem, mas é o meio de acessarmos e entendermos o mundo e nós mesmos.

Contudo, McDowell apresenta esse conceito de formação para salientar a importância da linguagem e de estar inserido em uma tradição, no contexto de Mente $e$ Mundo, a busca por razões para uma justificação estão conectadas com a tradição. A linguagem em sua relação com a experiência do mundo gera problemas em relação

análise da defesa de McDowell sobre o conteúdo da experiência e os pressupostos de Kant, McLEAR, Colin. The Kantian (Non)- Conceptualism Debate. In: Philosophy Compass, July 21, 2014.

RICHTER, Bruna Natália. Bildung e segunda natureza: Mcdowell leitor de Gadamer. Griot : Revista de Filosofia, Amargosa-BA, v.19, n.1, p.186-196, fevereiro, 2019. 
ao local do ser humano dentro da natureza, como McDowell fala, "A comparação dos animais sem linguagem conosco não pode exigir a separação entre sensibilidade e entendimento [...]"'(2005, p. 106). A modernidade alterou aquilo que entendemos como sendo natural, ela exclui a racionalidade da natureza acabando com as concepções aristotélicas dos seres humanos enquanto animais racionais pertencem à natureza. $O$ naturalismo nu e cru elimina o exame detalhado sobre a espontaneidade sustentando que "somos capazes de compreender naturalisticamente a ideia de espontaneidade, se a palavra 'naturalisticamente' for usada em acordo com a concepção de natureza que descrevi." (2005, p. 110), Como afirma McDowell isso quer dizer que devemos repensar a razão para que ela entre no conceito de natureza sem alterar nossa concepção de natureza. As consequências desse pensamento geram seres "metafisicamente cindidos" enquanto racionais. McDowell pretende defender que a razão é a forma que a natureza humana possui, a capacidade de responder a razões e a espontaneidade são pertencentes ao modo de viver que possuímos como nós realizamos enquanto animais. Para tanto, seria necessário expandir para além de um naturalismo pertencente ao reino da lei que é limitada pela nossa primeira natureza a aos fatos que ocorrem ao longo de nossa formação. A criação de um naturalismo de segunda natureza que situaria a espontaneidade na natureza sem reduzi-la no interior do reino da lei.

Não obstante, seria na formação de um caráter ético em que propiciaria uma disposição a sabedoria pratica que se tornaria uma segunda natureza, originária do pensamento de Aristóteles, nas palavras de McDowell,

\footnotetext{
Se generalizarmos o modo como Aristóteles concebe a modelagem do caráter ético, chegaremos a noção de possuir olhos abertos as razões em geral por meio da aquisição de uma segunda natureza. Não me ocorre nenhuma expressão curta da língua inglesa para traduzir esta ideia, mas é ela que está envolvida no sentido da palavra alemão Bildung. (2005, p. 122)
}

Assim, a espontaneidade se afirmaria no interior dessa segunda natureza, a partir da ideia de formação ao ser excluída do reino das leis. Dado que essa segunda natureza seria uma região do mundo natural com características particulares a si, essa realocação da espontaneidade é uma renúncia aos naturalismos. A Bildung assegura que a autonomia do significado não é inumana, por isso a categoria do social é importante. "A vida humana, nossa maneira natural de ser, está desde o começo conformada pelo significado." (2005, p. 134) O sentido que há em um texto não é no mesmo que nos eventos naturais, a defesa do reencantamento da natureza não exige uma reabilitação dos sentidos na natureza. $O$ reino da lei é carente de sentido segundo a modernidade, sua conexão não são relações que constituem o espaço das razões $(2005$, p. 136). Cabe agora colocar a filosofia de McDowell sobre a perspectiva crítica de Hilary Putnam (1982).

Putnam em seu artigo Why Reason Can't Be Naturalized (1982) faz duras críticas às teorias filosóficas que se baseiam na naturalização da razão e das noções fundamentais das teorias do conhecimento, como as noções que possuímos sobre as crenças como sendo justificadas ou mesmo racionalmente aceitáveis. As críticas de Putnam apontam também ao uso das noções de natureza que não clarificam o que 
entendem pela noção de natureza e as noções metafísicas tradicionais. Não obstante, teorias que tratam a razão como sendo uma capacidade de "descobrir verdades" (1982, p. 4), deste modo, nossas capacidades racionais dariam origem a crenças racionais, assim como a verdade dependeria da correspondência das nossas experiências com os fatos. Para Putnam,

\footnotetext{
Nós não possuímos noções como a de 'existência' dos objetos (coisas) ou mesmo a de 'verdade' das declarações que são independentes das versões que formamos e dos procedimentos e praticas que dão sentido para falar da 'existência' e da 'verdade' sem essas versões. ${ }^{7}(1982$, p. 4)
}

Putnam acredita que o conhecimento que formamos e as definições de verdade e do modo da existência dos objetos no mundo real deve ser revista. Tudo aquilo que entendemos ou que conhecemos nos é dado a partir dos sentidos, mas não possuímos uma condição que seja necessária e suficiente para afirmar que o objeto seja realmente como acreditamos que seja e que de fato algo seja verdade. Ele acredita que muitas teorias que não visam uma discussão mais detalhada desses conceitos corre o risco de "colapsar na vacuidade".

Não obstante, quando caracterizamos a racionalidade como uma "capacidade de descobrir verdades" se torna problemático, dado a ideia de verdade assim como de capacidade. Essa concepção se torna problemática, pois, não há como delimitar linhas precisas no cérebro entre uma capacidade e outra com precisão, em alguns casos o modo como o delimitamos na psicologia são bem diferentes entre uma e outra capacidade, mas o processo cerebral só pode ser interpretado a partir da observância do exterior, no ambiente, nos comportamentos que refletem o interesse visado.

\section{Segunda natureza e a vida dos animais}

A relevância de colocar em discussão as críticas de Putnam a naturalização do conceito de razão se mostra para uma clarificação da empreitada de McDowell. A narrativa do filósofo de Pittsburg trata da discussão de conceitos e teorias modernas a respeito de um novo conceito de natureza, que Putnam (2002) afirma ser uma concepção Galileana ou mesmo Newtoniana. A natureza se encontrando no espaço das leis que provêm do aristotelismo, do conceito de sabedoria prática, mas sem se envolver na discussão das causas finais. Contudo, essa concepção de natureza a partir da experiência de uma abertura para o mundo coloca também essa concepção no reino da razão. A influência que Davidson exerce em McDowell é mostrada no modo como ele apresenta as concepções de Kant como de espontaneidade. A natureza que McDowell afirma é uma segunda natureza para o ser humano em relação com a espontaneidade do entendimento e a Bildung. Em relação a razão, McDowell afirma,

A noção de racionalidade que pretendo evocar aqui é a noção explorada por uma linha de raciocínio tradicional que dá aos animais racionais um

\footnotetext{
7 We don't have notions of the "existence" of things or the "truth" of statements that are independent of the versions we construct ando f the procedures and practices that give sense to talk of the 'existence' and 'truth' within those versions. (PUTNAM, 1982, p. 4)
}

RICHTER, Bruna Natália. Bildung e segunda natureza: Mcdowell leitor de Gadamer. Griot : Revista de Filosofia, Amargosa-BA, v.19, n.1, p.186-196, fevereiro, 2019. 
lugar especial dentro do reino animal. Trata-se de uma noção de responsividade a razões enquanto tais. $(2006$, p.148)

Os animais são capazes de ter uma respostas ao meio ambiente, eles são capazes de fugir, isto é, responde a uma razão que o perigo próximo. Esse comportamento animais descrito desse modo é inteligível a partir da razão, mas isso não é uma razão enquanto tal (2006, p. 149). Não obstante, McDowell completa, "capacidades conceituais, no sentido que me interessa, pertencem essencialmente à racionalidade de quem as possui, racionalidade no sentido com o qual estou trabalhando, de responsividade a razões enquanto tais". (2006, p.150)

Para Gadamer a formação diz mais respeito ao resultado de um processo do devir do que o próprio processo enquanto tal que seria "uma constante transferência do devir para o ser" (2014, p. 46), isso quer dizer, que a formação é um processo que ocorre no interior de um ser humano que está em constante evolução e aperfeiçoamento de suas capacidades. Em relação à Bildung, ela diz respeito ao que toca às capacidades da espontaneidade do sujeito que a própria concepção de segunda natureza que Aristóteles tinha em mente. Bildung abre um lugar especial no domínio da autonomia em relação a natureza animal, pois a segunda natureza não nos liberta da natureza animal.

Os seres dotados de entendimento e capacidades conceituais são capazes de formar juízos sobre o mundo, de tomar algo como sendo verdadeiro. Esse ato de formar juízos é potencialmente autoconsciente, pois o sujeito tem consciência dele como sendo o formador do juízo e como aquele que dá as razões para aquele. A linguagem garante uma visão de mundo que nos dá uma abertura para os acontecimentos do mundo que são independentes de nós, e, que podem ser articulados discursivamente. Os demais animais não possuem esse mesmo acesso ao mundo dado que vivem em um ambiente, apenas os seres humanos experienciam o mundo como mundo.

Em Gadamer vemos a análise que Humboldt faz sobre as linguagens comparadas e a psicologia dos povos em que ele aponta haver uma "força do espírito humano" que estaria presente a partir da utilização da linguagem por grupos e comunidades. Cada uma dessas linguagens possui uma concepção de mundo própria, e o conjunto de todas não geraria a perda de suas devidas individualidades, para Gadamer,

\footnotetext{
A forma da linguagem e o conteúdo da tradição não podem ser separados na experiência hermenêutica. Se cada língua é uma concepção de mundo, ela não o é primeiramente como representante de um determinado tipo de língua (como o pesquisador de linguagem vê a língua), mas através do que se diz e se transmite nessa língua. (2014, p. 569).
}

Na experiência hermenêutica a multiplicidade de visões de mundo adquiridos pela linguagem não é algo conflitante, pois cada uma delas contém as demais, os horizontes que fazem parte de uma tradição não são fechados em si, mas abertos a uma fusão de horizontes que fazem parte dessa multiplicidade. $O$ uso de uma língua como no trato vivo com pessoas que compartilham essa língua, assim como estudo da literatura que proporcionam um novo ponto de vista na concepção de mundo. 
Os animais não-racionais, possuem capacidade sensórias como as do seres humanos, capaz de perceber estados de causalidade como mudanças em seu ambiente A sensorialidade é um traço da vida animal também em nosso caso. No caso dos seres humanos a espontaneidade é responsável por gerar a inteligibilidade do significa e por colocar os juízos no espaço das razões sui generis em relação ao reino da lei. Segundo McDowell, "O mundo objetivo está presente apenas para um sujeito autoconsciente, um sujeito capaz de atribuir experiências a si mesmo." (2005,p.152). Uma consciência do mundo depende da nossa capacidade de nos atribuir autoria das experiências que nos afetam. Somente a partir da espontaneidade que o mundo se torna visível para nós assim como nos da visibilidade de nós mesmo, pois essas capacidades dependem das capacidades conceituais, logo, da linguagem. Deste modo, animais sem espontaneidade do entendimento estão restritos, não são capazes de se atribuir experiências, nem reformulando constantemente as suas visões de mundo em respostas as experiências que recebem dele.

A linguagem instaura uma forma de existência autônoma, e ao nos desenvolvermos nela, ela nos introduz num determinado comportamento para com o mundo. Em Gadamer,

\footnotetext{
A linguagem não é somente um dentre muitos dotes atribuídos ao homem que está no mundo, mas serve de base absoluta para que os homens tenham mundo, nela se representa o mundo. Para o homem, o mundo está aí como mundo numa forma como não está para qualquer outro ser vivo que esteja no mundo. (2014, p. 571).
}

Ter um mundo e ter uma linguagem para expressar uma visão de mundo significa comportar-se perante o mundo, receber os dados sensórios do mundo, mas ao mesmo tempo manter nosso comportamento livre e distanciado, o mundo do ser humano não é um mundo circundante como os dos demais animais. Os animais estão à mercê dos "imperativos biológicos imediatos", sua sensorialidade e moldada em função desses imperativos que visam a permanência do indivíduo e da espécie, mas que como McDowell afirma não se reduzem a essa permanência. Uma vida vivida como produto imediato desses imperativos biológicos não se constitui como uma vida vivida em um mundo, mas sim em uma ambiente.

A partir das capacidades conceituais, seres humanos, podem lidar com os problemas e explorar as oportunidades de ação exercitando a espontaneidade para pensar e agir no mundo, seres humanos a despeitos dos demais animais não estão presos aos imperativos biológicos imediatos, isso ocorre a partir da segunda natureza e da espontaneidade que nos dá uma orientação para o mundo. A vida não é desse modo, somente uma resposta às sucessões de necessidades biológicas que possuímos. O que para Gadamer "Quase já não se pode contestar que o que caracteriza a relação do homem com o mundo, em oposição a todos os demais seres vivos, é a sua liberdade frente ao mundo circundante." (2014, p. 574) Seres humanos são passíveis de amadurecerem a medida que se desenvolvem no espaço das razões, a partir da sua vida no mundo, a linguagem em grande medida seria uma "corporificação" do metal e a possibilidade de nos orientarmos pelo mundo. 


\section{Conclusão}

No que toca a natureza da percepção, existe uma ampla discussão, sobre se a experiência é ou não conceitual. McDowell afirma contra Evans e demais filósofos que a natureza das experiências possuem conteúdos conceituais. Na modernidade com o desencantamento da natureza as capacidades de sensibilidade e espontaneidade enquanto pertencentes à natureza sofrem uma ruptura. Não obstante, para que tal ruptura não ocorrer, McDowell traz a discussão o conceito de Bildung que abrirá espaço para realocar a espontaneidade na natureza. A abertura para o mundo, alegada por McDowell, é baseada em uma orientação do entendimento de algo que vem nos afetar, segundo Rüdiger Bubner (2002). A espontaneidade nunca parte do nada, assim a tradição cumpre um papel importante na argumentação de McDowell, pois estamos inseridos em uma cultura permeada pela história. Deste modo, a espontaneidade não se reduz ao espaço lógico das leis e ao mesmo tempo com o conceito de formação estará no espaço das razões. Deste modo, através da ideia de uma segunda natureza nós podemos dizer que a racionalidade faz parte da natureza, e a natureza nesse sentido é peculiar, pois, possui uma relação de um lado com as nossas potencialidade biológicas que estão com nós desde o nascimento e do outro lado nossa potencialidade para a formação (Bildung). 


\section{Referências}

BOYLE, Matthew. Additive Theories of Rationality: A Critique. In: European Journal of Philosophy, 2016.

BRISCO, Stefano Di. Second Nature and Animal life. In: Between the species, Issue $\mathrm{X}$, August, 2010.

BUBNER, Rüdiger. Bildung and Second Nature. In: in N. H. Smith (a c. di), Reading McDowell, Routledge, 2002.

GADAMER, Hans-Georg. Verdade e Método I - Traços fundamentais de uma hermenêutica filosófica, Tradução de Flávio Paulo Meurer. 14a Ed. Petrópolis, RJ: Vozes. Bragança Paulista: Editora Universitária São Francisco, 2014.

GRONDIN, J. Vattimo's Latinization of Hermeneutics: Why Did Gadamer Resist Postmodernism? In: Weakening Philosophy: Essays in Honour of Gianni Vattimo, ed. S. Zabala. Montreal \& Kingston: McGill-Queen's University Press, 2007.

MARINO, Stefano. Seconda natura, liberta e corporeità. Alcune considerazioni su Gadamer e McDowell. In: Philosophical Readings III.1, 2011.

McDOWELL, John. Capacidades conceituais na percepção, Tradução de Herivelto Pereira de Souza. doispontos, Curitiba, São Carlos, vol. 3, n. 1, p.147-170, abril, 2006. McDOWELL, J. Mind and World. Cambridge (MA): Harvard University Press. 1996 McDOWELL, John. Mente e Mundo. Tradução de João Vergílio Gallerani Cuter. Aparecida, SP : Idéias \& Letras, 2005.

McDOWELL, John. Gadamer and Davidson on Understanding and Relativism. In : The Engaged Intellect: Philosophical Essays. Harvard University Press. p. 134-151, 2009.

McLEAR, Colin. The Kantian (Non)- Conceptualism Debate. In: Philosophy Compass, July 21, 2014.

NORRIS, Christopher. 'Second Nature', Knowledge and Normativity: revisiting McDowell's Kant. In: Diametros nr 27: 64-107, 2011.

PUTNAM, Hilary. Why reason can't be naturalized. Synthese52(1982) 3-23.

THANING, Morten S. The Problem of Objectivity in Gadamer's Hermeneutics in light of McDowell's Empiricism. Springer International Publishing Switzerland 2015.

THORNTON, T. John McDowell. Chesham: Acumen, 2004.

Autor(a) para correspondência: Bruna Natália Richter Universidade Federal de Santa Maria, Av. Roraima, 1000, Bairro Camobi, 97105-900, Santa Maria - RS, Brasil. brunataliarichter@gmail.com 